\title{
Кристаллическая структура и ширина запрещенной зоны твердых растворов $\left(\mathrm{MnIn}_{2} \mathrm{~S}_{4}\right)_{1-x} \cdot\left(\mathrm{Agln}_{5} \mathrm{~S}_{8}\right)_{x}$
}

\author{
(C) И.В. Боднарь, Чан Бинь Тхан \\ Белорусский государственный университет информатики и радиоэлектроники, \\ 220013 Минск, Беларусь \\ E-mail: chemzav@bsuir.by
}

(Получена 11 мая 2017 г. Принята к печати 22 мая 2017 г.)

\begin{abstract}
Методом Бриджмена впервые выращены монокристаллы твердых растворов $\left(\mathrm{MnIn}_{2} \mathrm{~S}_{4}\right)_{1-x} \cdot\left(\mathrm{AgIn}_{5} \mathrm{~S}_{8}\right)_{x}$ во всем интервале концентраций. Определен состав полученных монокристаллов и их кристаллическая структура. Показано, что твердые растворы кристаллизуются в кубической структуре шпинели. Рассчитан параметр элементарной ячейки монокристаллов $(a)$, и построена его концентрационная зависимость. Установлено, что $a$ c $x$ изменяется линейно. По спектрам пропускания в области края собственного поглощения определена ширина запрещенной зоны $\left(E_{g}\right)$ соединений $\mathrm{MnIn}_{2} \mathrm{~S}_{4}, \mathrm{AgIn}_{5} \mathrm{~S}_{8}$ и твердых растворов $\left(\mathrm{MnIn}_{2} \mathrm{~S}_{4}\right)_{1-x} \cdot\left(\mathrm{AgIn}_{5} \mathrm{~S}_{8}\right)_{x}$, построена ее концентрационная зависимость. Установлено, что $E_{g}$ с $x$ изменяется нелинейно (с максимумом при $x=0.4)$.
\end{abstract}

DOI: 10.21883/FTP.2018.08.46227.8643

\section{1. Введение}

Соединение $\mathrm{MnIn}_{2} \mathrm{~S}_{4}$ относится к магнитным полупроводникам типа $\mathrm{MB}_{2}^{\mathrm{III}} \mathrm{C}_{4}^{\mathrm{VI}}\left(\mathrm{M}-\mathrm{Mn}, \mathrm{Fe}, \mathrm{Co}, \mathrm{Ni} ; \mathrm{B}^{\mathrm{III}}-\right.$ $\mathrm{Al}, \mathrm{Ga}, \mathrm{In} ; \mathrm{C}^{\mathrm{VI}}$ - S, Se, Te). Соединение является перспективным материалом для создания на его основе лазеров, модуляторов света и других функциональных устройств, управляемых магнитным полем [1-6].

Соединение $\mathrm{AgIn}_{5} \mathrm{~S}_{8}$ относится к дефектным полупроводникам с концентрацией вакансий в катионной подрешетке, равной $\sim 25 \%$. Это соединение имеет $n$-тип проводимости, обладает высокой радиационной стойкостью и не испытывает влияния со стороны посторонних атомов, т.е. примеси являются электрически неактивными. Кристаллы $\mathrm{AgIn}_{5} \mathrm{~S}_{8}$ перспективны для создания фотопреобразователей солнечного излучения, электрооптических модуляторов и других устройств [7-9].

В настоящей работе представлены результаты выращивания монокристаллов соединений $\mathrm{MnIn}_{2} \mathrm{~S}_{4}, \mathrm{AgIn}_{5} \mathrm{~S}_{8}$ и твердых растворов $\left(\mathrm{MnIn}_{2} \mathrm{~S}_{4}\right)_{1-x} \cdot\left(\mathrm{AgIn}_{5} \mathrm{~S}_{8}\right)_{x}$, исследования их кристаллической структуры и спектров пропускания в области края фундаментального поглощения.

\section{2. Методика эксперимента}

Монокристаллы соединений $\mathrm{MnIn}_{2} \mathrm{~S}_{4}, \operatorname{AgIn}_{5} \mathrm{~S}_{8}$ и твердые растворы $\left(\mathrm{MnIn}_{2} \mathrm{~S}_{4}\right)_{1-x} \cdot\left(\mathrm{AgIn}_{5} \mathrm{~S}_{8}\right)_{x}$ предварительно синтезировали двухтемпературным методом. Элементарные компоненты (серебро, индий, марганец) чистотой $>99.999 \%$, взятые в соотношениях, соответствующих составу соединения или твердого раствора, загружали в кварцевую лодочку, которую располагали в одном конце кварцевой ампулы. В противоположном ее конце находилась сера, взятая с избытком от стехиометрии, необходимым для создания давления ее паров над расплавом $\sim 2.0$ атм. После откачки ампулы до оста- точного давления $\sim 10^{3}$ Па ее отпаивали от вакуумной системы и располагали в горизонтальной двухзонной печи таким образом, чтобы лодочка с металлическими компонентами находилась в „горячей“ зоне печи, а сера - в „холодной“ зоне. Температуру „горячей“ зоны устанавливали 1380-1420 K (в зависимости от типа соединения или состава твердого раствора). Температуру „холодной“ зоны повышали со скоростью $\sim 100 \mathrm{~K} /$ ч до $\sim 700 \mathrm{~K}$ и выдерживали в течение 2 ч для протекания реакции между металлическими компонентами и парами серы. Для более полного протекания этой реакции температуру с такой же скоростью повышали до $950 \mathrm{~K}$ с повторной выдержкой в течение 1 ч. По истечении указанного времени проводили направленную кристаллизацию расплава в зоне, где находились металлические компоненты, до температуры $800 \mathrm{~K}$ и печь отключали от сети.

Полученные поликристаллические слитки перегружали в двойные кварцевые ампулы. Внутренняя ампула заканчивалась цилиндрическим капилляром, который обеспечивал формирование монокристаллической затравки. К наружной ампуле снизу приваривали кварцевый стержень, служивший держателем. После вакуумирования ампулы ее помещали в вертикальную однозонную печь с заданным температурным градиентом, в которой проводили выращивание монокристаллов. Температуру печи повышали со скоростью $250 \mathrm{~K} /$ ч до температуры $1380-1420 \mathrm{~K}$ и для гомогенизации расплава, выдерживали при этой температуре в течение 2 ч. После указанного времени выдержки проводили направленную кристаллизацию расплава понижая температуру печи со скоростью $\sim(2-3) \mathrm{K} /$ ч до полного затвердевания расплава. Для гомогенизации полученных слитков их отжигали при $1170 \mathrm{~K}$ в течение 400 ч. Выращенные в таких условиях монокристаллы имели диаметр $\sim 16$ мм и длину $\sim 40$ мм, были однородными и гомогенными, 


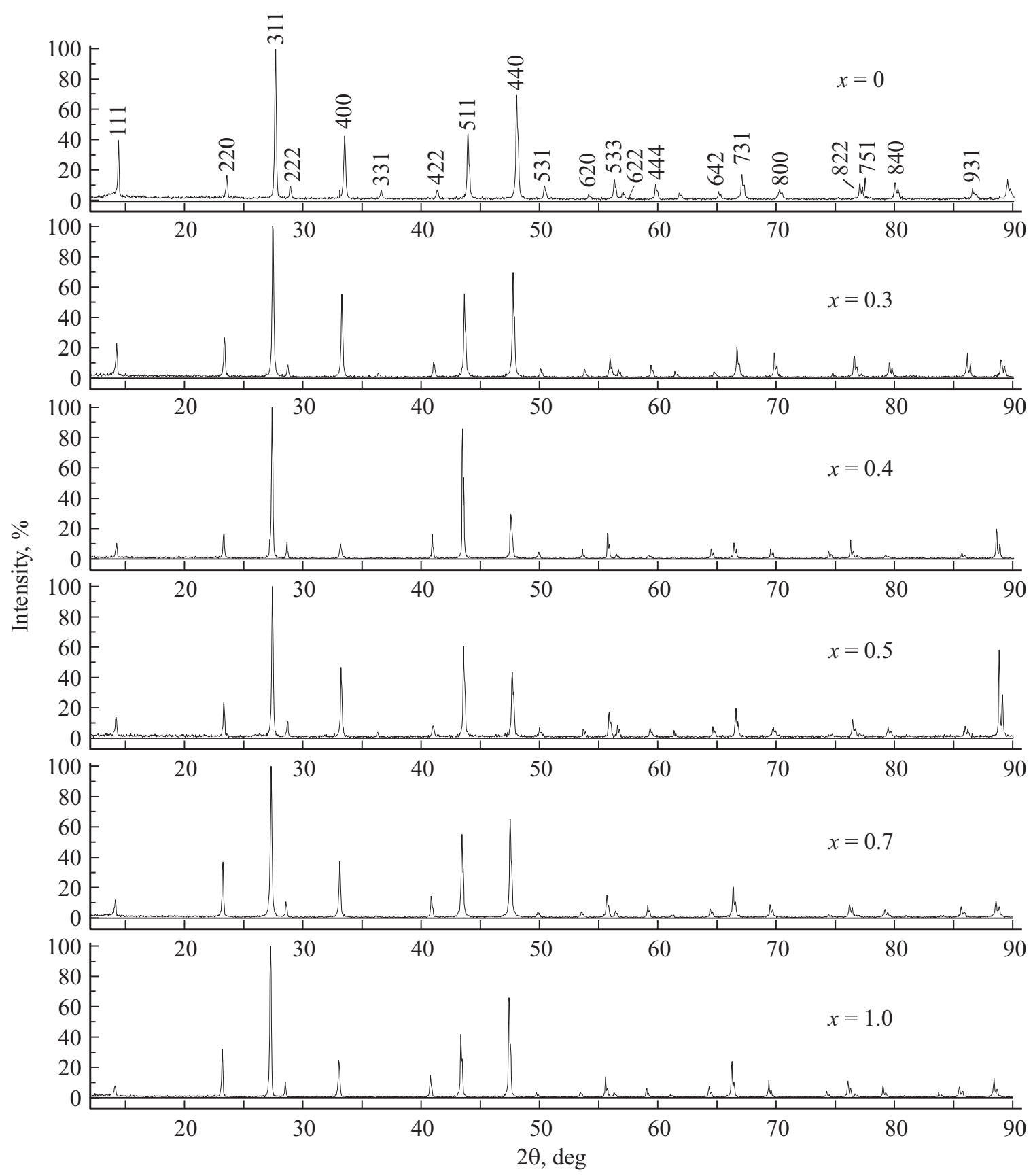

Рис. 1. Дифрактограммы исходных соединений $\mathrm{MnIn}_{2} \mathrm{~S}_{4}, \operatorname{AgIn}_{5} \mathrm{~S}_{8}$ и твердых растворов $\left(\mathrm{MnIn}_{2} \mathrm{~S}_{4}\right)_{1-x} \cdot\left(\operatorname{AgIn}_{5} \mathrm{~S}_{8}\right)_{x}$.

что установлено методами микрорентгеноспектрального и рентгеновского анализов.

Состав выращенных кристаллов определяли методом микрозондового рентгеноспектрального анализа, который проводили на установке „Сатеса-SX100“.

Структуру выращенных кристаллов определяли рентгеновским методом. Угловые положения линий дифракционного спектра записывали на рентгеновском дифрактометре ДРОН-3М в $\mathrm{Cu} K_{\alpha}$-излучении с графитовым монохроматором. Образцы для измерений готовили путем измельчения кристаллов и последующей их запрессовкой в специальном держателе. Для снятия ме- ханических напряжений, возникающих при растирании монокристаллов, проводили их отжиг в вакууме при температуре $700 \mathrm{~K}$ в течение 2 ч.

Спектры пропускания в области края собственного поглощения регистрировали на спектрофотометрах „Cary-500“ и „Proscan MC-121“. Для измерений из монокристаллов вырезали плоскопараллельные пластинки перпендикулярно оси роста кристаллов, которые затем механически шлифовали и полировали с двух сторон до толщин $\sim 20$ мкм. Для снятия нарушенного слоя, образовавшегося при механической обработке кристаллов непосредственно перед измерениями спект- 
Результаты рентгеноспектральных измерений

\begin{tabular}{|c|c|c|c|c|c|c|c|c|}
\hline \multirow{3}{*}{$x$} & \multicolumn{8}{|c|}{ Содержание элементов, ат\% } \\
\hline & \multicolumn{2}{|c|}{$\mathrm{Mn}$} & \multicolumn{2}{|r|}{$\mathrm{Ag}$} & \multicolumn{2}{|r|}{ In } & \multicolumn{2}{|r|}{$\mathrm{S}$} \\
\hline & расчет & эксперимент & расчет & эксперимент & расчет & эксперимент & расчет & эксперимент \\
\hline 0.0 & 14.29 & 14.12 & - & - & 28.57 & 28.20 & 57.14 & 57.68 \\
\hline 0.1 & 11.69 & 11.82 & 1.30 & 1.21 & 29.87 & 29.35 & 57.14 & 57.63 \\
\hline 0.3 & 7.69 & 7.57 & 3.30 & 3.45 & 31.87 & 32.04 & 57.14 & 56.94 \\
\hline 0.4 & 6.12 & 5.92 & 4.08 & 4.22 & 32.65 & 32.48 & 57.14 & 57.38 \\
\hline 0.5 & 4.76 & 4.91 & 4.76 & 4.66 & 33.34 & 33.24 & 57.14 & 57.19 \\
\hline 0.8 & 1.58 & 1.67 & 6.35 & 6.23 & 34.92 & 34.69 & 57.14 & 57.41 \\
\hline 0.9 & 0.75 & 0.72 & 6.77 & 6.84 & 35.34 & 35.43 & 57.14 & 57.00 \\
\hline 1.0 & - & - & 7.14 & 7.06 & 35.71 & 35.43 & 57.14 & 57.00 \\
\hline
\end{tabular}

ров образцы подвергали обработке в травителе состава $\mathrm{Br}_{2}: \mathrm{C}_{2} \mathrm{H}_{5} \mathrm{OH}=1: 3$.

\section{3. Экспериментальные результаты}

Данные микрорентгеноспектральных исследований представлены в таблице. Видно, что содержание компонент в выращенных монокристаллах соединений $\mathrm{MnIn}_{2} \mathrm{~S}_{4}, \mathrm{AgIn}_{5} \mathrm{~S}_{8}$ и твердых растворов $\left(\mathrm{MnIn}_{2} \mathrm{~S}_{4}\right)_{1-x} \cdot\left(\mathrm{AgIn}_{5} \mathrm{~S}_{8}\right)_{x}$ удовлетворительно согласуется с заданным составом в исходной шихте.

Дифрактограммы соединений $\mathrm{MnIn}_{2} \mathrm{~S}_{4}, \mathrm{AgIn}_{5} \mathrm{~S}_{8}$ и твердых растворов $\left(\mathrm{MnIn}_{2} \mathrm{~S}_{4}\right)_{1-x} \cdot\left(\mathrm{AgIn}_{5} \mathrm{~S}_{8}\right)_{x}$ представлены на рис. 1. Видно, что на дифрактограммах как соединений $\mathrm{MnIn}_{2} \mathrm{~S}_{4}$ и $\mathrm{AgIn}_{5} \mathrm{~S}_{8}$, так и твердых растворов на их основе присутствуют индексы отражений, характерные для кубической структуры шпинели. Для идентификации структуры полученных кристаллов и индицирования снятых дифрактограмм использовались данные картотеки центра дифракционных данных (International Center for Diffraction Data Joint Committee on Powder Diffraction Standards, ICDDJCPDS). Разрешение высокоугловых линий на дифрактограммах свидетельствует о равновесности соединений и гомогенности твердых растворов.

По измеренным значениям углов дифракции $2 \theta$ методом наименьших квадратов были рассчитаны параметры элементарной ячейки, которые для тройных соединений равны: $a=(10.722 \pm 0.005) \AA$ для $\mathrm{MnIn}_{2} \mathrm{~S}_{4}$ и $a=(10.827 \pm 0.005) \AA$ для $\operatorname{AgIn}_{5} \mathrm{~S}_{8}$. Изменение параметра $a$ для твердых растворов с $x$ оказалось линейным (рис. 2) (в соответствии с законом Вегарда), оно описывается следующим выражением:

$$
a=10.722+0.105 x,
$$

где $a$ измеряется в А̊.

Спектры пропускания соединений $\mathrm{MnIn}_{2} \mathrm{~S}_{4}, \mathrm{AgIn}_{5} \mathrm{~S}_{8}$ и твердых растворов $\left(\mathrm{MnIn}_{2} \mathrm{~S}_{4}\right)_{1-x} \cdot\left(\operatorname{AgIn}_{5} \mathrm{~S}_{8}\right)_{x}$ в области края собственного поглощения представлены на рис. 3. Видно, что величина пропускания указанных монокристаллов составляет $T>60 \%$.
Из зарегистрированных спектров пропускания рассчитывали коэффициент поглощения $\alpha$ по формуле, учитывающей многократное внутреннее отражение в плоскопараллельном образце [10]:

$$
\alpha=\frac{1}{d} \ln \left\{\frac{(1-R)^{2}}{2 T}+\sqrt{\left[\frac{(1-R)^{2}}{2 T}\right]^{2}+R^{2}}\right\}
$$

где $R$ - коэффициент отражения, $d$ - толщина образца.

На рис. 4 представлены спектральные зависимости $(\alpha \hbar \omega)^{2}$ от энергии фотона $(\hbar \omega)$ для тройных соединений и твердых растворов на их основе. Ширину запрещенной зоны $\left(E_{g}\right)$ определяли путем экстраполяции прямолинейных участков этой зависимости до пересечения с осью абсцисс. Нами получены следующие значения $E_{g}$ для исходных тройных соединений: 1.793 эВ для $\mathrm{AgIn}_{5} \mathrm{~S}_{8}$ и 1.968 эВ для $\mathrm{MnIn}_{2} \mathrm{~S}_{4}$. Наши данные удовлетворительно согласуются с результатами работ [6,7].

Концентрационная зависимость ширины запрещенной зоны для твердых растворов $\left(\mathrm{MnIn}_{2} \mathrm{~S}_{4}\right)_{1-x} \cdot\left(\mathrm{AgIn}_{5} \mathrm{~S}_{8}\right)_{x}$ представлена на рис. 5. Видно, что $E_{g}$ с параметром состава $x$ сначала возрастает от 1.793 эВ для соединения

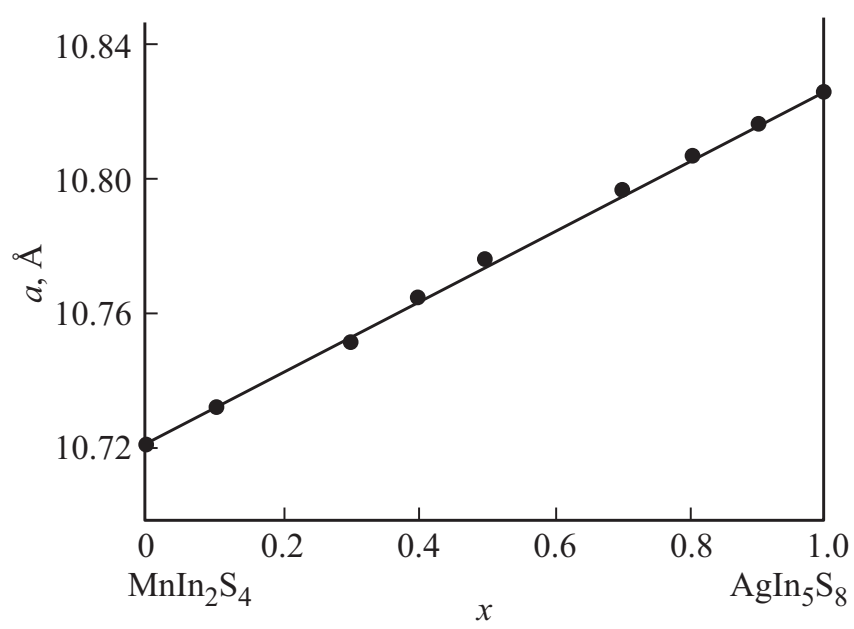

Рис. 2. Концентрационная зависимость параметра элементарной ячейки $a$ для твердых растворов $\left(\mathrm{MnIn}_{2} \mathrm{~S}_{4}\right)_{1-x} \cdot\left(\operatorname{AgIn}_{5} \mathrm{~S}_{8}\right)_{x}$. 
$\mathrm{AgIn}_{5} \mathrm{~S}_{8}$ до 2.092 эВ для состава с $x=0.4$, после чего уменьшается до 1.968 эВ для соединения $\mathrm{MnIn}_{2} \mathrm{~S}_{4}$. Такое поведение ширины запрещенной зоны можно объяснить, по-видимому, перестройкой кристаллической решетки в твердых растворах. Известно, что соединение $\mathrm{MnIn}_{2} \mathrm{~S}_{4}$ имеет структуру обращенной шпинели, а соединение $\mathrm{AgIn}_{5} \mathrm{~S}_{8}$ - структуру нормальной шпинели. При образовании твердых растворов, надо полагать, происходит перестройка кристаллической решетки от обращенной шпинели, характерной для соединения $\mathrm{MnIn}_{2} \mathrm{~S}_{4}$, к структуре нормальной шпинели, характерной для соединения

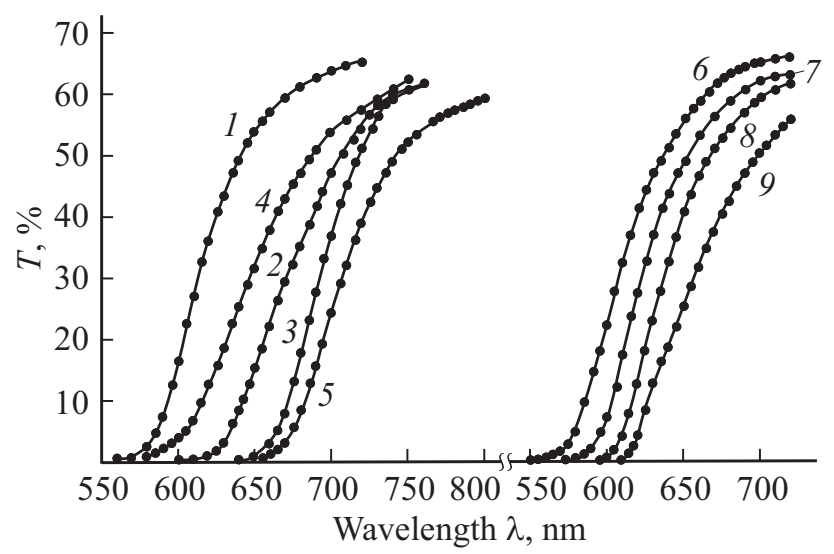

Рис. 3. Спектры пропускания монокристаллов $\mathrm{MnIn}_{2} \mathrm{~S}_{4}$, $\mathrm{AgIn}_{5} \mathrm{~S}_{8} \quad$ и твердых растворов $\left(\mathrm{MnIn}_{2} \mathrm{~S}_{4}\right)_{1-x} \cdot\left(\operatorname{AgIn}_{5} \mathrm{~S}_{8}\right)_{x}$ : $x=1.0$ (1), 0.9 (2), 0.8 (3), 0.7 (4), 0.5 (5), 0.4 (6), 0.0 (7), $0.2(8), 0.3(9)$.

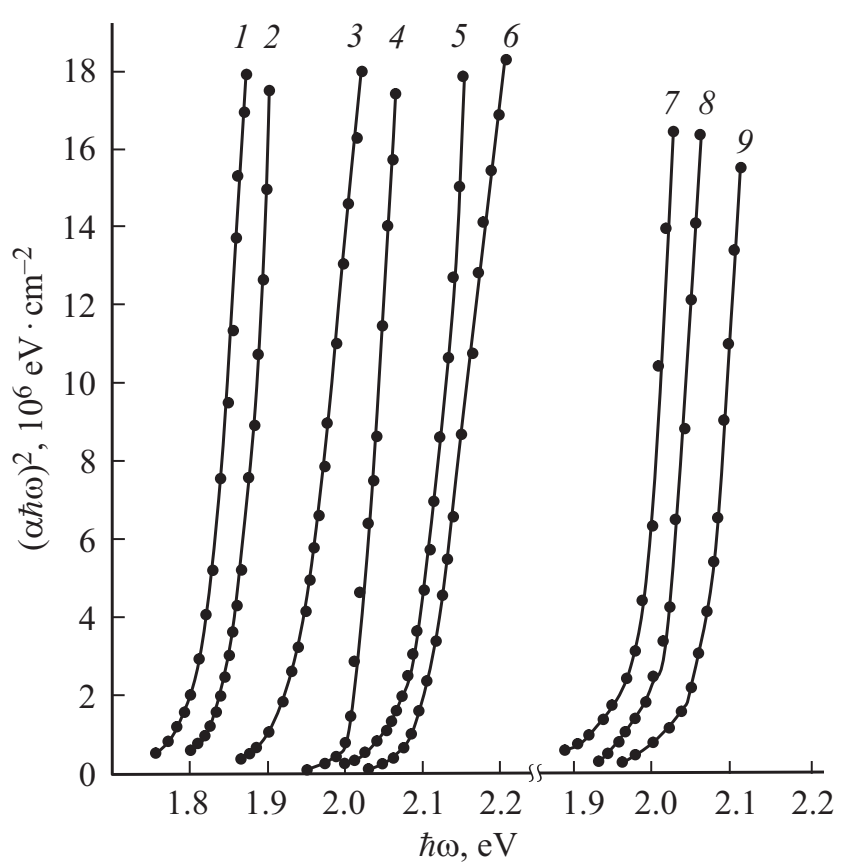

Рис. 4. Спектральные зависимости $(\alpha \hbar \omega)^{2}$ от $(\hbar \omega)$ для монокристаллов $\mathrm{MnIn}_{2} \mathrm{~S}_{4}, \operatorname{AgIn}_{5} \mathrm{~S}_{8}$ и твердых растворов $\left(\mathrm{MnIn}_{2} \mathrm{~S}_{4}\right)_{1-x} \cdot\left(\operatorname{AgIn}_{5} \mathrm{~S}_{8}\right)_{x}: x=1.0(1), 0.9$ (2), 0.8 (3), 0.7 (4), $0.5(5), 0.4(6), 0.0(7), 0.2(8), 0.3(9)$.

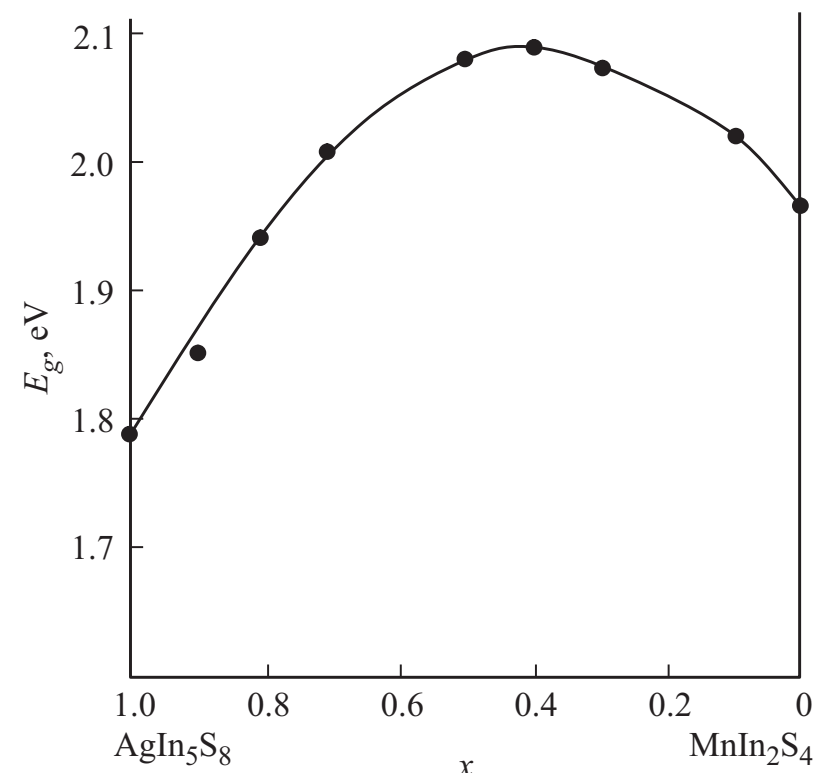

Рис. 5. Концентрационная зависимость ширины запрещенной зоны $E_{g}$ для монокристаллов твердых растворов $\left(\mathrm{MnIn}_{2} \mathrm{~S}_{4}\right)_{1-x} \cdot\left(\operatorname{AgIn}_{5} \mathrm{~S}_{8}\right)_{x}$.

$\mathrm{AgIn}_{5} \mathrm{~S}_{8}$. Такая перестройка приводит, вероятнее всего, к усилению химической связи для указанных твердых растворов.

Для описания поведения ширины запрещенной $E_{g}(x)$ для твердых растворов $\left(\mathrm{MnIn}_{2} \mathrm{~S}_{4}\right)_{1-x} \cdot\left(\operatorname{AgIn}_{5} \mathrm{~S}_{8}\right)_{x}$ была использована квадратичная зависимость следующего вида $[11,12]$ :

$$
E_{g}(x)=E_{A}+\left(E_{B}-E_{A}-c\right) x+c x^{2},
$$

где $E_{A}$ и $E_{B}$ - ширины запрешенной зоны исходных соединений $\mathrm{MnIn}_{2} \mathrm{~S}_{4}$ и $\mathrm{AgIn}_{5} \mathrm{~S}_{8}$, все энергии в эВ, $c-$ параметр нелинейности, который характеризует степень отклонения от линейной зависимости $E_{g}(x)$ для среднего состава $(x=0.5)$, определяемый из выражения

$$
\begin{gathered}
c=4 \Delta E(x=0.5), \\
\Delta E=\left(E_{A}+E_{B}\right) / 2-E_{g}(x=0.5) .
\end{gathered}
$$

Представленная концентрационная зависимость $E_{g}$ для твердых растворов $\left(\mathrm{MnIn}_{2} \mathrm{~S}_{4}\right)_{1-x} \cdot\left(\mathrm{AgIn}_{5} \mathrm{~S}_{8}\right)_{x}$ при $300 \mathrm{~K}$ описывается следующим выражением:

$$
E_{g}(x)=1.793+0.973 x-0.798 x^{2} .
$$

Расчетные значения $E_{g}(x)$ для твердых растворов на pис. 5 представлены сплошной линией. Видно, что экспериментальные данные удовлетворительно согласуются с расчетными величинами.

\section{4. Заключение}

Методом Бриджмена (вертикальный вариант) впервые выращены монокристаллы твердых растворов 
$\left(\mathrm{MnIn}_{2} \mathrm{~S}_{4}\right)_{x} \cdot\left(\operatorname{AgIn}_{5} \mathrm{~S}_{8}\right)_{1-x}$, определены их состав и структура. Установлено, что полученные монокристаллы имеют кубическую структуру шпинели. Методом наименьших квадратов рассчитаны параметры элементарной ячейки указанных твердых растворов, и построена их концентрационная зависимость. Установлено, что параметр элементарной ячейки с $x$ изменяется линейно. По спектрам пропускания в области края собственного поглощения определена ширина запрещенной зоны твердых растворов разного состава и построена ее концентрационная зависимость. Установлено, что $E_{g}$ с составом (c $x$ ) изменяется немонотонно, зависимость имеет максимум при $x=0.4$. Получена формула, которая хорошо описывает экспериментальную зависимость $E_{g}(x)$.

Работа выполнена при финансовой поддержке Белорусского Республиканского фонда фундаментальных исследований (проект № Ф16-028).

\section{Список литературы}

[1] 3. Метфессель, Д. Маттис. Магнитные полупроводники (М., Мир, 1972).

[2] I.V. Bodnar, S.V. Trukhanov, S.A. Pauliukavets, M.A. Novikova. J. Spintron. Magn. Nanomater., 1, 75 (2012).

[3] M. Leon, S. Levcenko, I.V. Bodnar, R. Serna, M. Guk, E.J. Friedrich, E. Arushanov. J. Phys. Chem. Sol., 73, 720 (2012).

[4] И.В. Боднарь, В.Ю. Рудь, Ю.В. Рудь. ФТП, 43, 1549 (2009).

[5] Н.Н. Нифтиев, О.Б. Тагиев. ФТП, 38, 164 (2004).

[6] J. Ruiz-Fuertes, D. Errandonea, F.J. Manjon, D. MartinezGarsia, A. Segura, V.V. Ursaki, I.M. Tiginyanu. J. Appl. Phys., 103, 063710 (2008).

[7] C. Paorici, L. Zanotti, N. Romeo, G. Sbeveglieri, L. Tarricone. Mater. Res. Bull., 34, 1207 (1977).

[8] A.F. Qasrawi. Thin Sol. Films, 516, 1116 (2008).

[9] A. Usujima, S. Takeuchi, S. Endo, T. Irie. Jpn. J. Appl. Phys., 20, L 505 (1981).

[10] Ю.И. Уханов. Оптические свойства полупроводников (М., Наука, 1977).

[11] J.A. Van Vechten, T.K. Bergstresser. Phys. Rev. B, 1, 3351 (1970).

[12] R. Hill. J. Phys. C, 7, 5231 (1974).

Редактор Л.В. Шаронова

\section{Crystal structure and band gap of $\left(\mathbf{M n l n}_{2} \mathrm{~S}_{4}\right)_{1-x} \cdot\left(\mathrm{Agln}_{5} \mathrm{~S}_{8}\right)_{x}$ solid solutions}

\section{I.V. Bodnar, Chan Bin Tkhan}

Belarusian State University of Informatics and Radioelectronics, 220013 Minsk, Belarus

Abstract Single crystals of $\left(\mathrm{MnIn}_{2} \mathrm{~S}_{4}\right)_{1-x} \cdot\left(\operatorname{AgIn}_{5} \mathrm{~S}_{8}\right)_{x}$ solid solutions have been obtained in the whole range of concentrations using Bridgeman method. Their crystal structure and the composition were determined. It was revealed that the solid solutions were crystallized in the spinal cubic structure. The parameters of the elementary cell $(a)$ was calculated and its concentration dependence was built. It was set that $a$ changed linearly with $x$. The band gap width $\left(E_{g}\right)$ of the compounds $\mathrm{MnIn}_{2} \mathrm{~S}_{4}, \mathrm{AgIn}_{5} \mathrm{~S}_{8}$ and of the solid solutions $\left(\mathrm{MnIn}_{2} \mathrm{~S}_{4}\right)_{1-x} \cdot\left(\mathrm{AgIn}_{5} \mathrm{~S}_{8}\right)_{x}$ was determined according to transmittance spectra at the edge of the fundamentalabsorption and its concentration dependence was built. $E_{g}$ with $x$ changed unlinearly (with $a$ maximum at $x=0.4$ ). 